International Review of Research in Open and Distributed Learning Volume 17, Number 4

June- 2016

\title{
Developing Guidelines for Evaluating the Adaptation of Accessible Web-Based Learning Materials
}

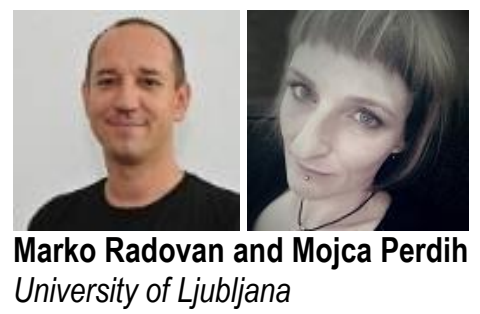

\begin{abstract}
E-learning is a rapidly developing form of education. One of the key characteristics of e-learning is flexibility, which enables easier access to knowledge for everyone. Information and communications technology (ICT), which is e-learning's main component, enables alternative means of accessing the webbased learning materials that comprise the content of e-learning. However, these materials can help provide a good educational experience only if they are designed carefully, which is especially true for people that have difficulties with learning from text or those with other learning disabilities (e.g., dyslexia). The main obstacle to learning for such people is usually posed by the form in which web-based learning materials are provided. Using guidelines from relevant literature, this article provides a checklist that assesses the degree to which web-based learning materials take account of the needs of people with disabilities, especially those with dyslexia. The article focuses more on the technical aspects of web-based learning materials, as they are a crucial factor that can influence the accessibility of web-based learning materials.
\end{abstract}

Keywords: e-learning, web-based learning materials, learning disabilities, dyslexia 


\section{Introduction}

Contemporary society perceives knowledge as both a source and a factor of a good quality of life. In the new social and technological circumstances, traditional educational concepts, and methods no longer suffice because they cannot cope with the increasing growth of knowledge. Each individual should have the opportunity to learn throughout his/her life. Hence, traditional educational systems should become more open and flexible and should be adapted to individual learning objectives, needs, and interests. E-learning can play a significant role in this regard because it supports new perspectives and possibilities of acquiring and creating knowledge (Allen \& Seaman, 2014; Fee, 2009; Simonson, Smaldino, Albright, \& Zvacek, 2012). One of its key characteristics is flexibility, which enables easier access to information for everyone (Brown \& Voltz, 2005; Sangrà, Vlachopoulos, \& Cabrera, 2012). Information and communications technology (ICT), which is e-learning's main component, enables alternative means of accessing the web-based learning materials that comprise the content of e-learning. If the materials are designed appropriately and allow for adaptation to individual needs, they can enable all types of learners, including those with dyslexia, to gain easier access to higher-quality educational content.

\section{Learning Disabilities and Web-Based Learning Materials}

According to the International Dyslexia Association (n.d.), 15-20\% of the global population has a languagebased learning disability; among the students with specific learning disabilities, 70-80\% have deficits in reading. Dyslexia is the most common cause of reading, writing, and spelling difficulties. There are a variety of definitions for dyslexia, which causes considerable confusion regarding how to identify it. Consequently, there is no unambiguous answer to the question of what dyslexia actually is (Camp \& Aldridge, 2007). However, the majority of definitions agree it is a difficulty related to reading, which also affects writing and spelling, and that the skills in these areas are below expectations with respect to the individual's age and intelligence (Doyle, 2002; McCarthy \& Swierenga, 2010). Definitions vary mainly in how authors perceive dyslexia. Some authors emphasize its neurological factors, while others focus on educational characteristics or stress cognitive factors. Therefore, it is always important to take context into account when defining dyslexia, which will subsequently enable us to find the most suitable adaptations for the individual's learning (Reid, 2009). The common ground all the theories share is the view of dyslexia as a developmental phenomenon that affects the individual for life, the main characteristic of which is difficulties in acquiring literacy skills. It is also important to note that there are numerous causes for dyslexia, including hereditary ones. According to Fitzgibbon and O'Connor (2002), the difficulties that are common to most adult dyslexics can be divided into the following three categories: difficulties with memory, difficulties with communication, and difficulties with organization and self-management. Bartlett, Moody, and Kindersley,. (2010) provide a more precise set of characteristics of a dyslexic person, listing difficulties in the areas of phonological skills, short-term memory, visuo-spatial skills, and sequencing (Bartlett, Moody, \& Kindersley, 2010).

When considering dyslexia, it is important to keep in mind that it may appear differently in each person, making it an "individual" difficulty, and that it may occur at different levels and in different combinations. Dyslexia does not depend on the individual's level of intelligence, effort, or socioeconomic circumstances. The most popular myths about dyslexia claim that it is a result of poor parenting, lack of educational opportunities, poor teaching, environmental factors, visual or hearing problems, or lack of motivation (Rief 
\& Stern, 2010). Dyslexia is often referred to as a "hidden disability" because it cannot always be noticed immediately since the individual can conceal it successfully for a long time. It is only noticed when such an individual faces a situation that requires her/him to demonstrate literacy skills or to process specific types of information (Reid, 2005).

\section{Assistance and Adaptations of Web-Based Learning Materials for Learners with Dyslexia}

It is especially important to be aware that the consequences of dyslexia are not compatible with the usual teaching methods. When addressing their various language-based learning disabilities, specific treatment, ICT, and specific teaching adaptations (e.g., methods, techniques) can be very effective. Here, the manner of preparing learning materials is of great importance. Rief and Stern (2010) claim that everybody can learn if only educators adapt instruction and educational materials. Educators should be able to take account of various learning needs and possess additional knowledge and skills concerning laws and principles that they can adapt for people with learning disabilities.

While ICT can be of great help to people with dyslexia or other language-based learning disabilities, it cannot completely replace structured teaching and learning. This is also due to the constant appearance of new technologies that are ceaselessly changing. Such ICT is changing both the educational process and the educational content. This is true not only of how the content is taught; ICT is providing learners with a mass of resources that are no longer solely passive since they include other media and interactive forms.

For people with dyslexia, assistive technology can indicate a move toward independent learning. It is important for such learners to know their weak and strong learning points well; how assistive technology can help them regarding their learning needs; and how using the technology can help them in developing learning independence. Assistive technology is understood as equipment and software that are used to maintain or improve the functional capabilities of a person with a disability (Doyle, 2002), examples of which include mp3 players, dictaphones, tablets, and PCs.

\section{Guidelines for Developing Web-Based Learning Materials}

The wide variety of materials available on the market includes self-study CDs, online courses, and countless study notes that are accessible online. It is vital for these materials to be prepared in an effective and organized manner and presented suitably in order to enable users to acquire, understand, and process information as easily as possible. This is even more critical if users include people with dyslexia.

There were some attempts to develop comprehensive guidelines for creating websites or web-based learning materials for dyslexic and other print-disabled persons (e.g., Cooper, 2006; Evett \& Brown, 2005; Phipps \& Kelly, 2006; Smythe \& Draffan, 2005). The main proponent of accessibilities standards is the World Wide Web Consortium ( $\mathrm{W}_{3} \mathrm{C}$ ). $\mathrm{W}_{3} \mathrm{C}$ (2008) developed a set of accessibility guidelines to improve the accessibility of the web content for people with disabilities. These guidelines, which were published under the Web Accessibility Initiative (WAI), are among the most complete resources for making all web content, tools, and agents more accessible. Phipps and Kelly (2006) stressed that the WAI's approach has some limitations. While they acknowledged the importance of the WAI's impact in raising awareness of web accessibility with their guidelines, they concluded that while these guidelines have a very important role to 
play in the creation of more generic web-based materials, it is difficult to relate the same approach to a rich e-learning experience that is accessible to all students. They proposed a "holistic" approach to supporting the development of e-learning resources that address the following issues: (a) usability; (b) making learning accessible; (c) making courses accessible; and (d) adapting to individual, local, political, and cultural factors. Cooper (2006) also developed some guidelines for general software accessibility, which are much more general than the guidelines developed by the $\mathrm{W}_{3} \mathrm{C}$ and are targeted at a general population of disabled students in higher education. Cooper's guidelines are as follows:

- Allow for user customization;

- Provide equivalent visual and auditory content and interface elements;

- Provide compatibility with assistive technologies;

- Allow access to all functionality from the keyboard alone;

- Provide context and orientation information (Cooper, 2006, pp. 112-113).

These attempts are focused more on usability or accessibility and tend to be more general in nature since they are focusing on software, technologies, and even general principles of facilitating learning. Our checklist includes a new category: readability (the complete checklist is in the appendix). This distinction follows the classification proposed by Smythte and Draffan (2005), who examined the adaptation of webbased learning materials for dyslexic users in greater detail. Since the authors of this article focus on the technical side of web-based learning materials, which mostly influences the reading competence of people with dyslexia, we adopted the abovementioned three key criteria. When drawing up "practical," "measurable" guidelines for each individual category, the authors relied on Rainger (2003) and Smythe (Smythe, 2010; Symthe \& Draffan, 2005), who put forward practical recommendations for developing webbased learning materials for users with dyslexia. Guidelines for each set of criteria were drawn up similarly to the previously mentioned guidelines for the development of web-based learning materials that are essential for people with dyslexia.

\section{Accessibility}

The accessibility of web-based learning materials is assessed according to whether or not a user with dyslexia can access information, regardless of how easy the materials are to use.

Enable access to materials via assistive technology. Users with dyslexia use different assistive technology, the most frequently used example of which is text-to-speech software. Therefore, the materials should be constructed in a manner that makes it available with such software (Smythe, 2010). For example, text that is embedded in Flash animation or inside pictures is not available to all text-to-speech converters. Some text-to-speech converters follow general reading rules and thus, for example, they read without a pause if there is no full stop at the end of a sentence. This can certainly have a major influence on the learning of those with dyslexia. To overcome such obstacles, full stops are required after bullet points/paragraphs, statements, phrases, (sub)titles, and (sub)headings. If the size of the punctuation is much smaller than the size of the heading font, the visual effect is minimal. 
Do not use only text to present information. The use of illustrations, diagrams, flow charts, and photographs can enhance the accessibility of web-based learning materials for people with dyslexia. For instance, procedures or processes are learnt more easily from pictures or illustrations than from text (Burt, 2004). The use of multimedia that supplements text also enhances accessibility for such users because they activate different learning channels. However, when using multimedia and other images, it is always necessary to offer a textual alternative, which will be discussed in more detail in the following section. Finally, it is crucial that the user controls such multimedia elements (i.e., the user starts, stops, and replays them).

Enable textual description of visual content. Presentation in different formats is, of course, important, yet it is important to ensure that there are always textual equivalents (Rainger, 2003). A short description of pictures, charts, and multimedia is essential. Designers should not rely on multimedia alone to ensure content presentation. Moreover, textual equivalents are also needed for greater accessibility to text-to-speech programs.

Make navigation easy to use. Navigating materials should be easy and intuitive. The provision of a site map is essential as it helps the user to have greater control over the materials. Most of all, it is important that a site map should be clearly separated from the body of the text and always visible to the user so that he/she can easily orient him-/herself (Rainger, 2003).

Enable the selection of the colors of the background and text as well as the font and typeface. Users should be able to customize the colors of the background and on-screen text as well as the fonts and typefaces. Various research studies demonstrate that such control over presentation has a significant influence on dyslexic users' ability to read accurately (McCarthy \& Swierenga, 2010).

\section{Usability}

Learning content may be accessible, but if it is not embedded in a user-friendly environment, it will not lead to an optimal educational/learning experience. As already stated, usability means how easily and how quickly people can learn from web-based learning materials. One possibility for assessing usability is counting the navigational errors that students make (i.e., their frequency and severity) (Smythe \& Draffan, 2005). The areas of usability the authors of this article focus on include typography (typeface, font size, leading/line spacing, justification), text, background color, and navigation. What follows is a set of guidelines that concern the abovementioned areas when designing web-based learning materials for users with dyslexia.

Offer at least three different typefaces. Researchers have suggested that Times New Roman is the best typeface for people with dyslexia since it is a serif typeface and thus helps lead the eye from one letter to the next. However, these conclusions mainly originate in printed material analyses. The increasingly widespread use of computers has suggested a preference for typefaces with clean lines (sans serif), such as Arial (Helvetica on the Mac), Sassoon, and Tiresias. The recent preference for sans serif typefaces is due to that fact that a small detail like the "curl feet" in Times New Roman may be lost on a computer screen (Smythe \& Draffan, 2005, p. 81). 
Many of the problems people with dyslexia experience when reading are connected with legibility, a measure of how easily a reader can distinguish individual letters or characters from each other. In one of the earliest studies, Bouma and Legein (1977) reported that "crowding" (difficulty recognizing letters) could limit letter and symbol recognition in dyslexic readers more strongly than in normal readers. Spinelli, De Luca, Judica, and Zoccolotti (2002) and Zorzi et al. (2012) confirmed Bouma and Legein's (1977) findings, which addressed an important aspect of legibility - letter spacing. Hillier's (2006) research and testing of recommended typefaces for dyslexic readers revealed that the main difficulties are primarily related to similarities in the design of the character forms, resulting in the swapping of letters or numbers (e.g., b/d, $\mathrm{p} / \mathrm{q}$, and 6/9).

Hillier (2006) established in his research that a majority of dyslexic readers preferred:

- handwritten style

- $\quad$ uppercase (Sylexiad) forms rather than lowercase forms

- $\quad$ long ascenders and descenders

- light weight

- uniform strokes

- perpendicular design

- generous inter-word spacing

- familiarity

- $\quad$ Serif Sylexiad (as a typeface family)

One of the most widely mentioned "dyslexia typefaces" is Read Regular (www.readregular.com), which was created by the Dutch designer Natascha Frensch. In his PhD dissertation, Rob Hillier (2006) examined dyslexia-friendly typefaces for adult Internet users and published his conclusions and his own typface 'Sylexiad' on his website (www.robsfonts.com). He developed typefaces as a result of user feedback (Hillier, 2006), however, such endeavors are usually destined to fail since the use of these typefaces is limited as they are not available free of charge. Another recommended typeface for people with dyslexia is Dyslexie, which was designed by Christian Boer (http://www.dyslexiefont.com/). In Boer's typeface, the letters are designed with heavier bottom portions to prevent the reader from turning them upside down. Renske de Leeuw (2010) researched and tested this typeface and found that reading Dyslexie did not increase reading speed, but it did result in fewer typical dyslexic reading errors.

It is important to keep in mind that these are only very general recommendations because not all dyslexic users have the same needs. Research also suggests that the typefaces individuals have used in the past frequently define their future choices as well. It is crucial to design web-based learning materials in a way that enables choosing different typefaces. 
Enable font size selection. People with dyslexia typically use fonts that are not smaller than 12 pt. (Zarach, 2012). Research conducted by Bernard, Liao, and Mills, (2001) shows that a 14-pt. font is more legible for adults and leads to faster reading than the usual 12-pt. fonts. However, Geske (2000) found that fonts greater than 12 point lead to a slower reading speed and that 12-point fonts are optimal. In addition, it is important not to neglect the fact that font size is also influenced by the selected typeface. Although several typefaces have been specifically designed for dyslexic readers (e.g., Dyslexie font; http://www.dyslexiefont.com or OpenDyslexic; http://opendyslexic.org), some studies demonstrated that using these fonts did not enhance text readability or reading speed (de Leeuw, 2010; Rello \& Baezo-Yates, 2013).

Typically, website designers set the default size, which users can then adjust by using the browser. However, designers have recently been building in simple accessibility tools in the form of buttons you click to instantly change the size of the text. Unfortunately, many websites use fonts that are too small for most dyslexic users, thus making them useless/inaccessible for these users. The ability to change font size quickly and easily is therefore crucial. A new study (Schneps, Thomson, Chen, Sonnert, \& Pomplun, 2013) shows that the students experienced significant reading improvements in speed and comprehension when using a handheld device configured to display only a few words of text per line.

Enable background and text color selection. Increasingly, websites offer users the possibility to change and adapt the background and text color and thus choose the way they view the learning environment. With Cascading Style Sheets (CSS)-templates that define what the website will look like in a browser and separate content from the website design-it is possible to create dynamically modifiable text and background colors (as well as typeface and font size) (Smythe \& Draffan, 2005). There are countless color combinations and it is hard to decide on the most appropriate one for each individual user. However, it is important that the user has a choice, and today's technology makes that possible.

The Web Accessibility Initiative (WAI) (http://www.w3.org/WAI/) has also developed some guidelines regarding background and text color combinations. Its recommendations initially emphasized the need for a high contrast level between color combinations, which may actually be inappropriate for many people with dyslexia (Smythe, 2010). Some people with dyslexia suffer from scotopic sensitivity syndrome, which means that their perception of the light spectrum differs from normal perceptions. When they see a black text on a white background, they find it difficult to make out letters or words in a line. They also usually report a dazzling/shining effect due to high contrasts. Instead of letters and words, they see moving and bending blots (Jordan, 1996). A dark text on a pale background is therefore recommended (e.g., a dark blue text on a cream background) (Rainger, 2003).

Content layout and navigation. Content layout is a frequently overlooked component in designing web-based learning materials. Imagine having a single screen with 62 clickable zones, including the browser itself (Smythe \& Draffan, 2005). Not only is such a content view confusing, it also leaves little space for learning. The placement of pictures and text is vital. Clarity and simplicity should be more important than the design and appearance of the material (Smythe \& Draffan, 2005). 
In light of the kind of problems dyslexic users have-e.g., they become easily confused and they have problems with remembering instructions-screen layout is very important. Therefore, good learning environments have very simple navigation that is hierarchical, always visible, and consistent throughout the material (Smythe, 2010). Orientation can be facilitated with navigation indicators, breadcrumb trails, highlighted/bold headings, or progress indicators so that the individual knows the exact location within the material's structure (Rainger, 2003). It is particularly important how hyperlinks are used in the text. They are usually underlined and in the same color so that the user can recognize them as hyperlinks; however, orientation is easier if a visited link is provided in a different color so that the individual knows whether he/she has already visited the site (Smythe \& Draffan, 2005). Finding items and moving around the material should be obvious and intuitive for users. Having mastered the navigation system, the user should not have to learn it all over again every time.

Avoid horizontal scrolling. Another thing to consider is how information is provided page by page. There is a choice between the style typically found in books and scrolling. They latter may be more difficult for users with coordination problems; however, alternative navigation is possible, such as draggable scroll bars, arrows, etc. (Smythe \& Draffan, 2005).

In any case, horizontal scrolling should be avoided since it affects text scanning. In general, the ideal line length is between 60 and 80 characters, although people usually read faster when lines are between 30 and 50 characters long. Columns are not really useful on websites because they require the user to scroll up and down on the screen. Hence, good learning content designers use short sections that take up the middle or right side of the screen (Smythe \& Draffan, 2005).

Use greater line spacing than usual and only used left-aligned, unjustified text. Most designers use default settings for line spacing (20\%, which means that if a 20 pt. font is used, the line spacing will be 24 pt.). However, people with dyslexia usually prefer somewhat greater spacing (c. 30\%) (Smythe \& Draffan, 2005). In addition to aesthetic appeal, increased line spacing ensures greater visual separation between descenders (the letters "g," "j," "p," and "q") and ascenders (the letters "b," "d," "f," "h," "k," "l," and " $\mathrm{t}$ "). If the space between them is insufficient, these letters can blend together and cause reading difficulties for people with dyslexia (Smythe, 2010). However, it is crucial to also avoid making the spacing too great as this will also make reading more difficult for these users.

Text should be left justified, which provides dyslexic users with a jagged pattern down the right side of the page (Smythe \& Draffan, 2005). Justified text causes uneven inter-word spacing and confuses users with dyslexia because excessive "white space" makes connecting words more difficult and thus slows down reading (Rainger, 2003).

\section{Readability}

Readability is another aspect of web-based learning material design, and it refers to the ease of reading and understanding a text in terms of the vocabulary and syntax used. Readability also depends on the use of typography (font, size, line height, etc.), a topic which was already covered in previous chapters. There are several ways to measure readability. Rudolf Flesch (1943) made an early attempt to establish a readability formula, using a scale from o to 100 (with o equivalent to the 12th grade and 100 equivalent to the 4 th 
grade) to predict the difficulty of adult reading material. His formula was later recalculated to give a gradelevel score. The new formula is now called the Flesch-Kincaid grade-level formula, which is one of the most popular formulas for measuring readability (DuBay, 2007). Newer studies have also measured readability with eye-tracking technology (Rello et al., 2013).

- Smythe and Draffan (2005) and Rainger (2003) created some simple criteria for assessing Internet material "readability," which is also important for dyslexic users: The average sentence length should be between 15 and 20 words.

- Information should be explicit; at the beginning, the learning objectives, and expectations should be emphasized.

- Instructions should be given clearly and without lengthy explanations.

- Use bullet points or numbering where appropriate.

- Use graphics to illustrate and explain any complex text.

- Introduce new concepts only when previous ones are consolidated.

- Use headings and subheadings to facilitate orientation.

- Use bold fonts or highlighting to emphasize important information.

- Do not use paragraphs in italics since this writing is more difficult to read.

- Use the active voice rather than the passive voice.

- Avoid underlining except for hyperlinks.

- Summarize content in mind maps or boxes.

\section{Checklist for Assessing the Adaptation of Web-based Learning Materials}

Subsequently, we developed a checklist on the basis of the above usability, accessibility and readability guidelines to assess web-based learning materials (see Appendix A). Our aim is that with using these guidelines a person can evaluate to what degree web-based learning materials actually follow these guidelines and in which areas they still need improvements.

Our checklist is founded on previous literature reviews, research, and guidelines (e.g., McCarthy \& Swierenga, 2010; Smythe \& Draffan, 2005; W3C, 2008; Zarach, 2002). Zarach (2002) developed 10 principles aimed at enhancing readability for people with dyslexia. Although these guidelines are primarily for people with dyslexia, Zarach (2002) pointed out that they can also benefit people without dyslexia through improving simplicity, clarity, and usability. The same is true for our checklist, which is applicable for both dyslexic and non-dyslexic readers. 


\section{Limitations of the Present Study}

The main conclusion of our review is that authors, web developers, and others involved in the development of e-materials should consider the different factors that influence texts' usability and readability for people with dyslexia. We must, of course, stress that the main findings for developing these guidelines were collected and combined from qualitative and quantitative studies carried out mainly in English-speaking countries. From other research on the universality of dyslexia, we know that the phenomenon of dyslexia is very diverse; even if there is an agreement of universality on a neurological level, its manifestations across countries are different, and so are its detection (Vellutino, Fletcher, Snowling, \& Scanlon, 2004). As noted by Serrano and Defior (2008), in languages with shallow orthographies (e.g., Spanish), dyslexia manifestations are more related to reading speed than to reading accuracy. This makes it difficult to detect dyslexia, as well as to develop some universal recommendations for facilitating reading for dyslexics from different language areas. Vellutino, Fletcher, Snowling, and Scanlon (2004) even describe dyslexia as a "hidden disability." Therefore, we cannot be certain all dyslexics would benefit equally from our checklist, and it should not be seen as a definitive checklist but as a starting point for future development and discussions.

\section{Conclusion}

Today's information society is characterized by each individual having constant and instant access to knowledge, which requires him/her to be able to look for, transmit, and use information that is freely available to everyone. Although multimedia has become an important part of our knowledge-based society, the abilities to read and write remain crucial to understanding complex materials. Furthermore, these abilities are conditions for social and "digital" integration (Torrisi \& Piangerelli, 2010). People with dyslexia remain a marginalized group due to the difficulties they face. Although reading and writing difficulties can be ameliorated to a degree with the help of various technologies, the problems can persist if specific adaptations are not provided. Thus, it is vital that online service developers realize what problems this group of individuals faces when using the Internet and strive for continuous improvements in accessibility and usability for such users. Nowadays, web-based learning materials are an ever-more frequent form and choice of education and learning, especially among adults. Such materials provide learners with flexibility regarding the space, time, and tempo of learning and also serve their different learning styles. Despite all the positive effects that web-based learning materials may have, they can also present a major obstacle, particularly for people with special needs (such as people with dyslexia). Without adequate adaptations (i.e., both the execution and design of web-based learning materials), some individuals remain excluded since access to and use of information in these materials can be particularly difficult for them. 


\section{References}

Allen, I. E., \& Seaman, J. (2014, January). Grade change: Tracking online education in the United States. Babson Survey Research Group. Retrieved from http://www.onlinelearningsurvey.com/reports/gradechange.pdf

Bartlett, D., Moody, S., \& Kindersley, K. (2010). Dyslexia in the workplace: an introductory guide (2nd ed). Malden, MA: Wiley-Blackwell.

Bernard, M., Liao, C., \& Mills, M. (2001). Determining the best online font for older adults. Software Usability Research Lab, 3(1). Retrieved from http://usabilitynews.org/determining-the-best-onlinefont-for-older-adults/

Bouma, H., \& Legein, C. P. (1977). Foveal and parafoveal recognition of letters and words by dyslexics and by average readers. Neuropsychologia, 15(1), 69-80. Retrieved from http://doi.org/10.1016/00283932(77)90116-6

Brown, A. R., \& Voltz, B. D. (2005). Elements of effective e-learning design. International Review of Research in Open and Distance Learning, 6(1). Retrieved from http://eprints.qut.edu.au/4381/

Burt, P. (2004). Design guidelines for effective e-learning materials. Retrieved from http://www.paulburt.co.uk/e-learning/e-learn design.pdf

Camp, D., \& Aldridge, J. (2007). Rethinking dyslexia, scripted reading, and federal mandates: The more things change, the more they stay the same. Journal of Instructional Psychology, 34(1), 3-12.

Cooper, M. (2006). Making online learning accessible to disabled students: an institutional case study. ALT-J, Research in Learning Technology, 14(1), 103-115. Retrieved from http://doi.org/10.1080/09687760500479779

de Leeuw, R. (2010). Special font for dyslexia? (Unpublished master's thesis). University of Twente, Holland.

Doyle, J. (2002). Dyslexia: An introductory guide. London: Whurr Publishers.

DuBay, W. H. (2007). Smart language: Readers, readability, and the grading of text. Costa Mesa, Calif.: Impact Information.

Dyslexie Font: The dyslexia font which eases the reading. (n.d.). Retrieved from http://www.dyslexiefont.com/

Evett, L., \& Brown, D. (2005). Text formats and web design for visually impaired and dyslexic readersClear Text for All. Interacting with Computers, 17(4), 453-472. Retrieved from http://doi.org/10.1016/j.intcom.2005.04.001 
Fee, K. (2009). Delivering e-learning. A complete strategy for design, application and assessment. Philadelphia: Kogan Page.

Flesch, R. (1943). Marks of readable style: A study in adult education. New York: Teachers College, Columbia University.

Fitzgibbon, G., \& O'Connor, B. (2002). Adult dyslexia: A guide for the workplace. Chichester: John Wiley \& Sons.

Geske, J. (2000). Readability of body text in computer mediated communications: Effects of type family, size and face. Retrieved from http://www.public.iastate.edu/ geske/scholarship.html

Hillier, R. A. (2006). A typeface for the adult dyslexic reader (Doctoral dissertation). Anglia Ruskin University. Retrieved from http://www.robsfonts.com/Resources/thesis.pdf

International Dyslexia Association. (n.d.). Frequently asked questions about dyslexia. Retrieved from http://eida.org/frequently-asked-questions-2/

Jordan, D. R. (1996). Teaching adults with learning disabilities. Malabar, Fla: Krieger Publishing Company.

McCarthy, J. E., \& Swierenga, S. J. (2010). What we know about dyslexia and Web accessibility: a research review. Universal Access in the Information Society, 9(2), 147-152. Retrieved from http://doi.org/10.1007/s10209-009-0160-5

Phipps, L., \& Kelly, B. (2006). Holistic approaches to e-learning accessibility. ALT-J, Research in Learning Technology, 14(1), 69-78. Retrieved from http://doi.org/10.1080/09687760500479860

Rainger, P. (2003). A dyslexic perspective on e-content accessibility. TechDis. Retrieved from http://www.techdis.ac.uk/seven/papers

Reid, G. (2005). Dyslexia and inclusion classroom approaches for assessment, teaching and learning . London: David Fulton. Retrieved from http://site.ebrary.com/id/10603155

Reid, G. (2009). Dyslexia: A practitioner's handbook (4th ed). Malden, Mass: Wiley-Blackwell.

Rello, L., \& Baeza-Yates, R. (2013, October). Good fonts for dyslexia. Paper presented at the ASSETS 2013: The 15th International ACM SIGACCESS Conference of Computers and Accessibility, Bellevue, Washington USA. Retrieved from http://assets13.sigaccess.org/

Rief, S. F., \& Stern, J. M. (2010). The dyslexia checklist: A practical reference for parents and teachers. San Francisco, Calif: Jossey-Bass. 
Sangrà, A., Vlachopoulos, D., \& Cabrera, N. (2012). Building an inclusive definition of e-learning: An approach to the conceptual framework. The International Review of Research in Open and Distance Learning, 13(2), 145-159.

Schneps, M. H., Thomson, J. M., Chen, C., Sonnert, G., \& Pomplun, M. (2013). E-readers are more effective than paper for some with dyslexia. PLoS ONE, 8(9), e75634. Retrieved from http://doi.org/10.1371/journal.pone.0075634

Serrano, F., \& Defior, S. (2008). Dyslexia speed problems in a transparent orthography. Annals of Dyslexia, 58(1), 81-95. Retrieved from http://doi.org/10.1007/s11881-008-0013-6

Simonson, M. R., Smaldino, S. E., Albright, M., \& Zvacek, S. (2012). Teaching and learning at a distance: Foundations of distance education (5th ed). Boston: Allyn \& Bacon.

Smythe, I. (2010). Dyslexia in the digital age: Making IT work. New York: Continuum International Publishing Group.

Smythe, I., \& Draffan, E. A. (2005). Dyslexia and e-learning - a guide to good practice. In I. Smythe (Ed.), Provision and use of Information technology with dyslexic students in university in Europe (pp. 79-86). Retrieved from http://eprints.soton.ac.uk/264150/1/The Book.pdf

Spinelli, D., De Luca, M., Judica, A., \& Zoccolotti, P. (2002). Crowding effects on word identification in developmental dyslexia. Cortex, 38(2), 179-200. Retrieved from http://doi.org/10.1016/Soo109452(08)70649-X

Torrisi, G., \& Piangerelli, S. (2010). How new technologies can help with "invisible disabilities.” eLearning Papers, (19), 1-7.

Vellutino, F. R., Fletcher, J. M., Snowling, M. J., \& Scanlon, D. M. (2004). Specific reading disability (dyslexia): what have we learned in the past four decades? Journal of Child Psychology and Psychiatry, 45(1), 2-40. Retrieved from http://doi.org/10.1046/j.0021-9630.2003.00305

W3C. (2008). Web Content Accessibility Guidelines (WCAG) 2.o. Retrieved from https://www.w3.org/TR/WCAG/

Zarach, V. (2002). Ten guidelines for improving accessibility for people with dyslexia. Retrieved from http://wiki.cetis.ac.uk/Ten_Guidelines_for_Improving_Accessibility_for_People_with_Dyslexia

Zorzi, M., Barbiero, C., Facoetti, A., Lonciari, I., Carrozzi, M., Montico, M., ... Ziegler, J. C. (2012). Extralarge letter spacing improves reading in dyslexia. In Proceedings of the National Academy of Sciences, 109(28), 11455-11459. Retrieved from http://doi.org/10.1073/pnas.1205566109 


\section{Appendix A}

A proposed "Checklist for Assessing the Adaptation of Web-based learning materials to People with Dyslexia” (Possible answers: Yes; No; N/A)

\section{Accessibility Indicators}

1. The material enables access via assistive technology (text to speech).

2. The material contains navigation.

3. The navigation is clearly separated from the content.

4. The material contains controllers to regulate font sizes.

5. The material contains controllers to regulate typefaces.

6. The material contains controllers to regulate background and text colours.

7. The material does not consist of text only.

8. The material enables listening to the whole of material.

9. The content is supported with pictures, charts, illustrations.

10. The content is supported with animations.

11. The content is supported with audio recordings.

12. The content is supported with video recordings.

13. Pictures, illustrations, diagrams have their equivalents.

14. Audio recordings have their equivalents.

15. Video recordings have their equivalents.

16. Animations have their equivalents.

17. Audio and video recordings and animations can be started by the user.

18. Audio and video recordings and animations can be paused by the user.

19. Audio and video recordings and animations can be replayed by the user.

20. The material does not contain flashing elements that cannot be stopped. 


\section{Usability Indicators}

1. The material uses a sans serif typeface (Verdana, Arial, Georgia, Tahoma, Trebuchet, Comic Sans).

2. The font size is at least $12 \mathrm{pt}$.

3. The colour contrasts used in the material are gentle (pastel) and not sharp (white text on black background).

4. The site map is hierarchical and it gives an overview of the complete material by using headings and subheadings.

5. The material contains navigation forward/back buttons.

6. The material contains breadcrumb trails.

7. The material contains a progress indicator, so that it is always clear where in the material's structure we are (coloured or ticked (sub)heading in the site map).

8. When we want to return to the beginning or to a specific section, we do not have to go through all the sections.

9. The form and navigation of the material remain consistent throughout the material (the navigation is always in the same place and always visible).

10. Textual hyperlinks are coloured when they have been clicked.

11. Textual hyperlinks use a consistent form (e.g. blue underlined).

12. Hyperlinks in any form (buttons, graphics, text) are descriptive and we know where they will take us (not "click here").

13. The content is provided on one screen with minimal vertical scrolling.

14. There is no horizontal scrolling.

15. The material is divided into short paragraphs.

16. The text is in the middle or on the right side of the screen and does not take up the whole screen.

17. The material uses left text justification.

18. The text is not crammed; it uses adequate line spacing (at least 1.5). 


\section{Readability Indicators}

1. The average sentence length is between 15 and 20 words.

2. At the beginning key information is emphasized (learning objectives, expectations, instructions).

3. Instructions are given clearly and without lengthy explanations.

4. The text has clearly visible headings and subheadings.

5. Important information is in bold or highlighted.

6. Sentences are not written in italics.

7. Bullet points are used for better clarity.

8. Graphics are used better to illustrate and explain any complex text.

9. New concepts are explained in glossaries, icons in legends.

10. Boxes and mind maps are used to summarize important points.

11. The material provides suggestions, additional explanations and links at the side or in drop-down menus or when moving the mouse over a text.

12. The material uses the active voice, not the passive.

13. The material does not contain large chunks of underlined text which is not hyperlinks.

\section{Athabasca \\ University}

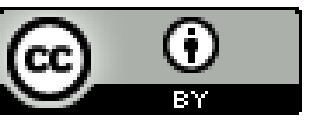

